\title{
Meta-analysis of the effect of antithrombotic drugs on perioperative bleeding in BPH surgery
}

\author{
QIAN HE, YANLAN YU and FENGBIN GAO \\ Department of Urology, Sir Run-Run Shaw Hospital, College of Medicine, \\ Zhejiang University, Hangzhou, Zhejiang 310000, P.R. China
}

Received December 6, 2019; Accepted June 23, 2020

DOI: $10.3892 /$ etm.2020.9102

\begin{abstract}
Effects of antithrombotic agents on the bleeding risk after transurethral resection of the prostate (TURP) were assessed in patients with benign prostatic hyperplasia (BPH). Controlled clinical trials on the effects of perioperative anticoagulant therapy on postoperative bleeding in BPH patients published during January 1990 and February 2019 were searched in PubMed, Embase and the Cochrane Library. Two independent reviewers screened the studies according to the inclusion and exclusion criteria, extracted the data, evaluated the quality, and conducted a meta-analysis using the RevMan 5.3 software. A total of 20 studies were included. Analysis of these studies found that compared with interrupted use of antithrombotic agents, continuous use of antithrombotic drugs led to more frequent post-TURP bleeding $(\mathrm{OR}=4.34,95 \% \mathrm{CI}=2.29-8.23)$, and higher transfusion rate $(2.96,1.19-7.36)$. Compared with patients who never used antithrombotic agents, those who used antithrombotic agents continuously had higher bleeding risk (5.52, 1.64-18.66). Those who continued using antithrombotic agents during laser treatment had higher transfusion rate than those who stopped using them before the operation (5.39, 1.49-19.53), but it had no significant difference in clot retention, blood transfusion rate, intraoperative hemoglobin decrease and postoperative catheter-indwelling time compared with those who never used antithrombotic agents $(\mathrm{P}>0.05)$. Those who continued using antithrombotic agents during TURP showed less intraoperative hemoglobin decrease $(-0.46,-0.58$ -0.35) than the patients who underwent low molecular weight heparin substitution. Interruption of antithrombotic agents during TURP can prevent the risk of postoperative bleeding; continuous use of antithrombotic agents is safe and feasible during laser treatment of BPH; whether low molecular weight heparin substitution is necessary during the discontinuation of antithrombotic agents is controversial.
\end{abstract}

Correspondence to: Dr Qian He, Department of Urology, Sir Run-Run Shaw Hospital, College of Medicine, Zhejiang University, 3 East Qingchun Road, Hangzhou, Zhejiang 310000, P.R. China E-mail: 3309060@zju.edu.cn

Key words: antithrombotic drugs, perioperative bleeding, benign prostatic hyperplasia, meta-analysis

\section{Introduction}

Benign prostatic hyperplasia (BPH) is a common and frequently encountered disease in middle-aged and old males (1). The incidence of BPH in males is $~ 40 \%$ at the age of 50 and $\sim 90 \%$ after the age of 80 years $(2,3)$.

The transurethral resection of the prostate (TURP) is the gold standard of BPH surgical treatment in men with prostate size of 30-80 ml (4). In recent years, holmium laser, $2 \mu \mathrm{m}$ laser and green laser have been widely used among clinicians for their excellent coagulation hemostasis and non-conductive properties. Two-micrometer laser is a high-energy laser with a wavelength of $2 \mu \mathrm{m}$, which is close to the maximum absorption peak of $1.94 \mu \mathrm{m}$ of water. It can be absorbed by the water in the tissue and produce a thermal effect, effectively achieving the purpose of cutting and vaporizing the tissue, with little heat loss to the surgical area (5). However, intraoperative and postoperative bleeding is still the main complication of surgical treatment (6). With the aging of the population and the increase of the incidence of cardiovascular and cerebrovascular diseases, the number of BPH patients requiring surgical treatment while taking oral antithrombotic drugs is also increasing year by year, further increasing the risk of perioperative bleeding (7). However, recent studies have found that the type of antithrombotic agents is not a major factor in the risk of perioperative bleeding in patients with BPH $(8,9)$. Meskawi et al (9) treated BPH patients undergoing laser surgery with antiplatelet agents such as clopidogrel acetylsalicylate and anticoagulants such as warfarin, thrombin inhibitors and rivaroxaban. However, they found no significant difference in the effect of different antithrombotic drugs on the risk of bleeding. So the effect of antithrombotic drugs on bleeding risk may be related to other factors. A large number of studies considered that antithrombotic drugs will increase the risk of perioperative bleeding, and it is recommended to interrupt anticoagulation preoperatively (10). However, some studies have pointed out that the risk of cardiovascular and cerebrovascular events after stopping antithrombotic drugs is three times higher than that of the group that did not stop using antithrombotic drugs (11). Therefore, this study adopted the method of systematic review to evaluate the impact of continuous use of antithrombotic drugs on intraoperative and postoperative bleeding risk of $\mathrm{BPH}$ patients, aiming to provide theoretical basis for clinical treatment decisions. 


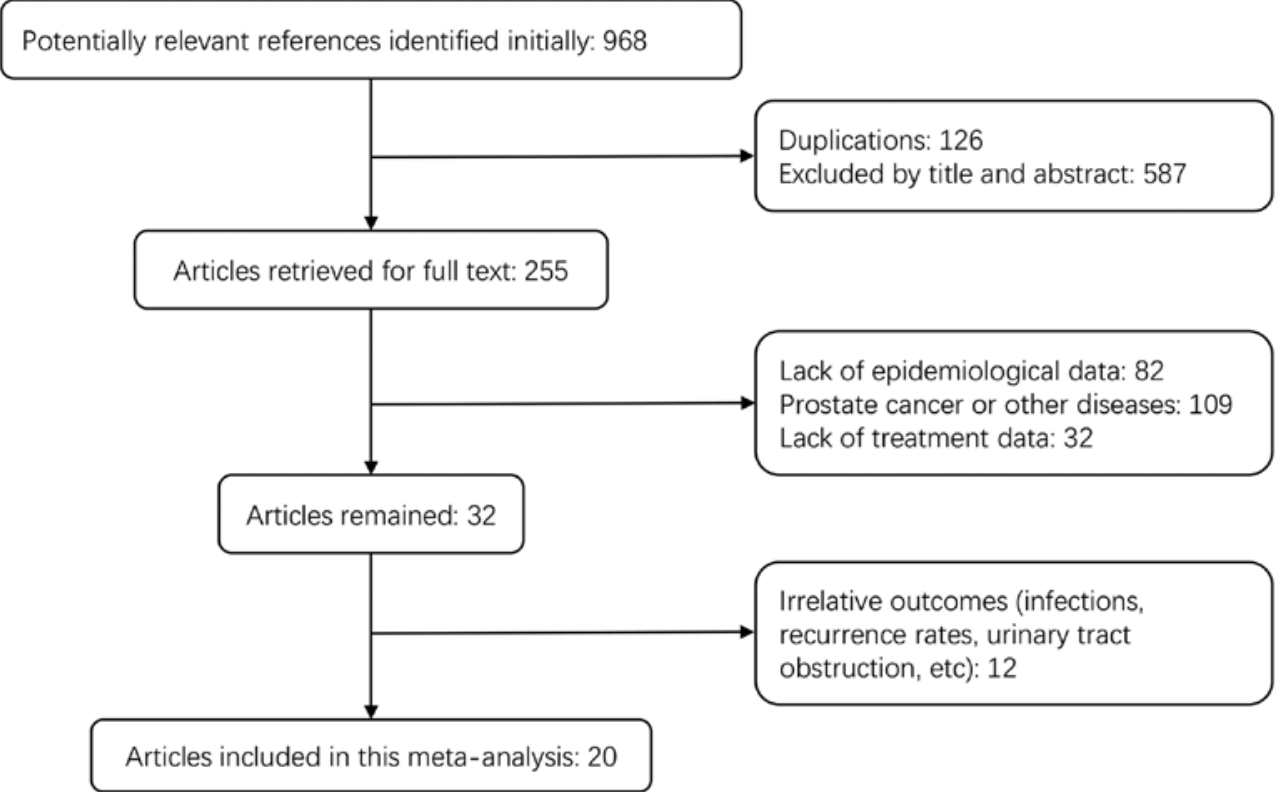

Figure 1. Study flow and selection diagram.

\section{Materials and methods}

Search strategy. We searched Pubmed, Embase and Cochrane library databases. The search terms were 'antithrombotic or aspirin or antiplatelet or heparin' and 'prostatic hyperplasia', and limited fields in the title and abstract. In order to increase the search efficiency, we also excluded the studies with keywords 'meta-analysis', 'review' and 'case report'. The time of publication was from inception to February 28, 2019. In addition, we searched the reference list of acquired articles manually.

Inclusion and exclusion criteria. Inclusion criteria: i) Type of study: Clinical controlled trial. ii) Study subjects: prostate surgery patients (including electric resection and laser surgery). iii) Intervention measures: experimental group, perioperative continuous application of antithrombotic drugs (including antiplatelet drugs and anticoagulant drugs), continuous use of antithrombotic drugs was defined as the patients did not stop using antithrombotic drugs during the surgery. Control group, antithrombotic drugs were discontinued preoperatively or not. The discontinued antithrombotic drugs were defined as drugs were discontinued preoperatively for 5-10 days, and anticoagulants, including novel oral anticoagulants-NOACs, were not used in discontinued patients during discontinuation. The unused antithrombotic drugs were defined as drugs were never taken or discontinued preoperatively for more than 30 days. iv) At least one outcome index was reported: incidence of postoperative bleeding, blood transfusion rate, decreased intraoperative hemoglobin, catheterization duration and incidence of cardiovascular and cerebrovascular events.

Exclusion criteria: i) The studies were repeatedly published; ii) No control group was set up in the study; iii) Incomplete information or unable to obtain complete information of the study.
Data extraction and quality assessment. Study screening and data extraction were performed independently by two reviewers. Firstly, the related studies were selected by browsing the title and abstract of the article. After excluding the studies that did not meet the inclusion criteria, the full text of the studies that might meet the inclusion criteria was searched and read, and then screened again. Two researchers cross-checked the included studies. For the studies with differences and difficult to reach consensus, the third researcher was asked to decide.

The extracted data included: i) basic information of the included studies, including author, publication time, country or region where the study was carried out, and sample size; ii) drugs and surgical methods; iii) anticoagulation mode and outcome indicators; iv) study quality evaluation of the relevant information.

Two researchers evaluated the quality of the included studies according to the Newcastle Ottawa scale (NOS) (12), and the third reviewer evaluated the studies when the scores were inconsistent. The full score of NOS score is 9, and the evaluation content includes the selection and exposure factors of the case control study, the comparability between groups, etc. The score of more than 6 is divided into high-quality study.

Observed indicator. Antithrombotic agents and bleeding risk after transurethral therapy of benign prostatic hyperplasia were evaluated by the following observed indicator: Incidence of postoperative bleeding, blood transfusion rate, decreased intraoperative hemoglobin, catheterization duration and incidence of cardiovascular and cerebrovascular events.

Statistical analysis. RevMan5.3 software was used to complete the meta-analysis process. Mean difference (MD) and $95 \%$ confidence interval $(95 \% \mathrm{CI})$ was used for measurement data, 
Table I. Basic characteristics of the included studies.

\begin{tabular}{|c|c|c|c|c|c|c|c|}
\hline \multirow[b]{2}{*}{ Authors, year (ref.) } & \multirow[b]{2}{*}{$\begin{array}{l}\text { Antithrombotic } \\
\text { therapy }\end{array}$} & \multirow[b]{2}{*}{$\begin{array}{l}\text { Surgical } \\
\text { procedures }\end{array}$} & \multicolumn{4}{|c|}{ Perioperative anticoagulation } & \multirow[b]{2}{*}{ Outcome } \\
\hline & & & $\begin{array}{l}\text { Persistent- } \\
\text { usage }\end{array}$ & Heparin & Discontinued & $\begin{array}{l}\text { Not } \\
\text { taking }\end{array}$ & \\
\hline Watson et al, 1990 (13) & Aspirin & TURP & 5 & - & - & 34 & $\mathrm{a}$ \\
\hline Thurston and Briant, 1993 (14) & Aspirin & TURP & 14 & - & - & 111 & $\mathrm{a}$ \\
\hline $\begin{array}{l}\text { Ala-Opas and } \\
\text { Grönlund, } 1996 \text { (15) }\end{array}$ & Aspirin & TURP & 40 & - & - & 42 & a \\
\hline Nielsen et al, 2000 (16) & Aspirin & TURP & 26 & - & 27 & - & $\mathrm{b}, \mathrm{e}$ \\
\hline Wenders et al, 2012 (17) & Aspirin & TURP & 42 & - & 156 & - & $a, b$ \\
\hline Dotan et al, 2002 (18) & Anticoagulant drugs & TURP & 20 & - & - & 20 & $\mathrm{~b}$ \\
\hline Taylor et al, 2011 (19) & Anticoagulant drugs & TURP & 7 & - & 65 & 91 & $a, b, e$ \\
\hline Ong et al, 2015 (20) & Antiplatelet drugs & TURP & 32 & - & 69 & 166 & $a, b, e$ \\
\hline Carmignani et al, 2014 (21) & Antiplatelet drugs & ThuLEP & 42 & - & - & 50 & $\mathrm{~b}$ \\
\hline Elzayat et al, 2006 (22) & Anticoagulant drugs & HoLEP & 14 & 34 & 33 & - & $\mathrm{b}$ \\
\hline Tyson and Lerner, 2009 (23) & Anticoagulant drugs & HoLEP & 38 & - & - & 37 & $\mathrm{~d}$ \\
\hline Bishop et al, 2013 (24) & Anticoagulant drugs & HoLEP & 52 & - & 73 & - & $\mathrm{b}$ \\
\hline El Tayeb et al, 2016 (25) & Anticoagulant drugs & HoLEP & 30 & - & 86 & - & $\mathrm{b}$ \\
\hline Sun et al, 2018 (26) & Antiplatelet drugs & HoLEP & 128 & - & 41 & 955 & $\mathrm{~b}, \mathrm{c}$ \\
\hline Ruszat et al, 2007 (27) & Anticoagulant drugs & PVP & 116 & - & - & 92 & d \\
\hline Karatas et al, 2010 (28) & Anticoagulant drugs & PVP & 9 & - & 58 & - & $\mathrm{c}, \mathrm{d}$ \\
\hline Sohn et al, 2011 (29) & Anticoagulant drugs & PVP & 30 & - & 30 & - & $\mathrm{c}$ \\
\hline Knapp et al, 2017 (30) & Anticoagulant drugs & PVP & 101 & - & - & 272 & $\mathrm{~d}$ \\
\hline Macchione et al, 2013 (31) & Anticoagulant drugs & ThuVARP & 41 & 35 & - & - & $\mathrm{b}, \mathrm{c}, \mathrm{d}$ \\
\hline Sener et al, 2017 (32) & Anticoagulant drugs & ThuVARP & 56 & 47 & - & - & $\mathrm{b}, \mathrm{c}, \mathrm{d}$ \\
\hline
\end{tabular}

a, Incidence of postoperative bleeding; b, blood transfusion rate; c, decreased intraoperative hemoglobin; d, catheterization duration; e, incidence of cardiovascular and cerebrovascular events.

odds ratio (OR) and $95 \%$ CI was used for categorical data, and $\mathrm{P}<0.05$ was considered statistically significant. The statistical heterogeneity among the studies was analyzed by Chi-square test, and the studies with good homogeneity $(\mathrm{P}>0.05$ and $\left.\mathrm{I}^{2}<50 \%\right)$ were analyzed with the fixed-effect model. If there is heterogeneity $\left(\mathrm{P}<0.05\right.$ or $\left.\mathrm{I}^{2}>50 \%\right)$, the source of heterogeneity will be analyzed. If there is no obvious heterogeneity, the random effect model will be used for analysis. If there is heterogeneity, the stability and reliability of the results can be verified by subgroup analysis or sensitivity analysis.

\section{Results}

Study selection and study characteristics. A total of 20 studies (13-32) were included in this analysis and the study screening process is shown in Fig. 1. Baseline data of included studies are shown in Table I. Among them, 8 studies (13-20) reported TURP and 5 studies (22-30) reported holmium laser enucleation of the prostate (HoLEP). Four studies (27-30) reported photoselective vaporization of the prostate (PVP). Thulium laser vaporesection of the prostate (ThuVARP) was used as surgical methods in 2 studies $(31,32)$ and 1 study (21) reported thulium laser enucleation of the prostate (ThuLEP). The quality assessment of the included studies is shown in Table II.
TURP: Persistent-usage group vs. discontinued group. Three studies reported incidence of postoperative bleeding and incidence of cardiovascular and cerebrovascular events, and four studies reported blood transfusion rates. Compared with the discontinued group, the persistent-usage group has a high incidence of postoperative bleeding $(\mathrm{OR}=4.34,95 \% \mathrm{CI}=2.29-8.23)$ and blood transfusion rate (2.96, 1.19-7.36), while the difference in the incidence of cardiovascular and cerebrovascular events is not statistically significant (0.76, 0.14-4.18) (Fig. 2).

TURP: Persistent-usage group vs. not taking group. The incidence of postoperative bleeding was reported in four studies, with obvious heterogeneity among studies. The random effect model was performed, and the results showed that the incidence of postoperative bleeding was high in the persistent-usage group $(5.52,1.64-18.66)$. Three studies reported that transfusion rates were higher in the persistent-usage group than that in not taking group (4.97, 1.73-14.28) (Fig. 3).

Laser surgery: Persistent-usage group vs. discontinued group. Blood transfusion rates were reported in three studies, and were higher in the persistent-usage group than that in the discontinued group $(5.39,1.49-19.53)$. Three different studies reported decreased intraoperative hemoglobin, with 
Table II. NOS scores of the included studies.

Authors

year (ref.)

Selection Comparability Exposure Total

\begin{tabular}{|c|c|c|c|c|}
\hline $\begin{array}{l}\text { Watson et al, } \\
1990(13)\end{array}$ & 3 & 1 & 2 & 6 \\
\hline $\begin{array}{l}\text { Thurston and } \\
\text { Briant, } 1993 \text { (14) }\end{array}$ & 3 & 2 & 2 & 7 \\
\hline $\begin{array}{l}\text { Ala-Opas and } \\
\text { Grönlund } 1996 \text { (15) }\end{array}$ & 3 & 2 & 2 & 7 \\
\hline $\begin{array}{l}\text { Nielsen et al, } \\
2000 \text { (16) }\end{array}$ & 2 & 1 & 1 & 4 \\
\hline $\begin{array}{l}\text { Wenders et al, } \\
2012 \text { (17) }\end{array}$ & 4 & 2 & 2 & 8 \\
\hline $\begin{array}{l}\text { Dotan et al, } \\
2002(18)\end{array}$ & 4 & 2 & 2 & 8 \\
\hline $\begin{array}{l}\text { Taylor et al, } \\
2011 \text { (19) }\end{array}$ & 3 & 1 & 2 & 6 \\
\hline $\begin{array}{l}\text { Ong et al, } \\
2015(20)\end{array}$ & 4 & 1 & 3 & 8 \\
\hline $\begin{array}{l}\text { Carmignani et al, } \\
2014(21)\end{array}$ & 4 & 1 & 2 & 7 \\
\hline $\begin{array}{l}\text { Elzayat et al, } \\
2006(22)\end{array}$ & 3 & 2 & 2 & 7 \\
\hline $\begin{array}{l}\text { Tyson and Lerner, } \\
2009 \text { (23) }\end{array}$ & 4 & 2 & 2 & 8 \\
\hline $\begin{array}{l}\text { Bishop et al, } \\
2013(24)\end{array}$ & 3 & 2 & 2 & 7 \\
\hline $\begin{array}{l}\text { El Tayeb et al, } \\
2016(25)\end{array}$ & 4 & 1 & 2 & 7 \\
\hline $\begin{array}{l}\text { Sun et al, } \\
2018(26)\end{array}$ & 4 & 2 & 2 & 8 \\
\hline $\begin{array}{l}\text { Ruszat et al, } \\
2007 \text { (27) }\end{array}$ & 4 & 2 & 2 & 8 \\
\hline $\begin{array}{l}\text { Karatas et al, } \\
2010(28)\end{array}$ & 3 & 1 & 2 & 6 \\
\hline $\begin{array}{l}\text { Sohn et al, } \\
2011 \text { (29) }\end{array}$ & 4 & 1 & 2 & 7 \\
\hline $\begin{array}{l}\text { Knapp et al, } \\
2017(30)\end{array}$ & 4 & 2 & 3 & 9 \\
\hline $\begin{array}{l}\text { Macchione et al, } \\
2013(31)\end{array}$ & 3 & 1 & 2 & 6 \\
\hline $\begin{array}{l}\text { Sener et al, } \\
2017(32)\end{array}$ & 4 & 2 & 3 & 9 \\
\hline
\end{tabular}

NOS, Newcastle Ottawa Scale.

no statistically significant difference between the groups (0.00, -0.03-0.03) (Fig. 4).

Laser surgery: Persistent-usage group vs. not taking group. Two studies reported blood transfusion rates and three reported catheterization duration. The results showed that there was no significant difference in blood transfusion rate $(1.56,0.18-13.59)$ and catheterization duration $(0.15,-0.17-0.47)$ between the two groups (Fig. 5).
Laser surgery: Persistent-usage group vs. heparin group. Three studies reported blood transfusion rates, and two reported decreased intraoperative hemoglobin and catheterization duration. Compared with the heparin group, the persistent-usage group had a lower intraoperative decreased intraoperative hemoglobin $(-0.46,-0.58--0.35)$. There was no significant difference in blood transfusion rate $(1.22,0.36-4.14)$ and catheterization duration (-0.04, -0.33-0.25) (Fig. 6).

\section{Discussion}

In recent years, the number of patients requiring oral antithrombotic drugs due to cardiovascular and cerebrovascular diseases increased rapidly, and there was great controversy over the perioperative anticoagulation management of these patients, especially the intraoperative and postoperative bleeding (33). Due to the lack of high-quality RCT studies, urologists currently have no unified consensus on the management of antithrombotic drugs, relying only on long-term clinical experience or existing observational studies. Although American Urological Association and International Consultation on Urological diseases has submitted a proposal on urology common surgical perioperative management of antithrombotic drugs, the number of articles in view of the prostate surgery was too small, therefore, it is necessary to perform a meta-analysis of the existing studies.

The meta-analysis results of TURP with or without continuous use of antithrombotic drugs during the perioperative period showed that continuous use of antithrombotic drugs would increase the incidence of postoperative bleeding and increase the possibility of blood transfusion, and the discontinuation of antithrombotic drugs 5-10 days before surgery could reduce postoperative bleeding complications. However, there was no significant difference in the incidence of perioperative cardiovascular and cerebrovascular events between the persistent-usage group and discontinued group. Whether the application of perioperative drugs was continuous was not random except for the study by Nielsen et al (16), and it was determined according to the risk of patients' cardiovascular and cerebrovascular events, which may reduce the incidence of perioperative cardiovascular and cerebrovascular events after drug withdrawal. In general, continuous use of antithrombotic drugs during the perioperative period of TURP will lead to more bleeding complications. For patients with low risk of thrombosis who take antithrombotic drugs for the prevention of cardiovascular and cerebrovascular diseases, it is recommended to stop using antithrombotic drugs preoperatively. In addition, some studies have found that the risk of thromboembolism is related to the operative time. The risk of thromboembolism increases with the length of surgery $(34,35)$. However, the included studies lacked relevant data, so large sample studies were expected to analyze the relationship between the risk of thromboembolism and the operative time.

In the meta-analysis of laser BPH surgery perioperative continuous and disable or unused antithrombotic drugs, there are three results showing the blood transfusion rate of the persistent-usage group was higher than that of the discontinued group. After analysis, the international normalized 
A Incidence of postoperative bleeding

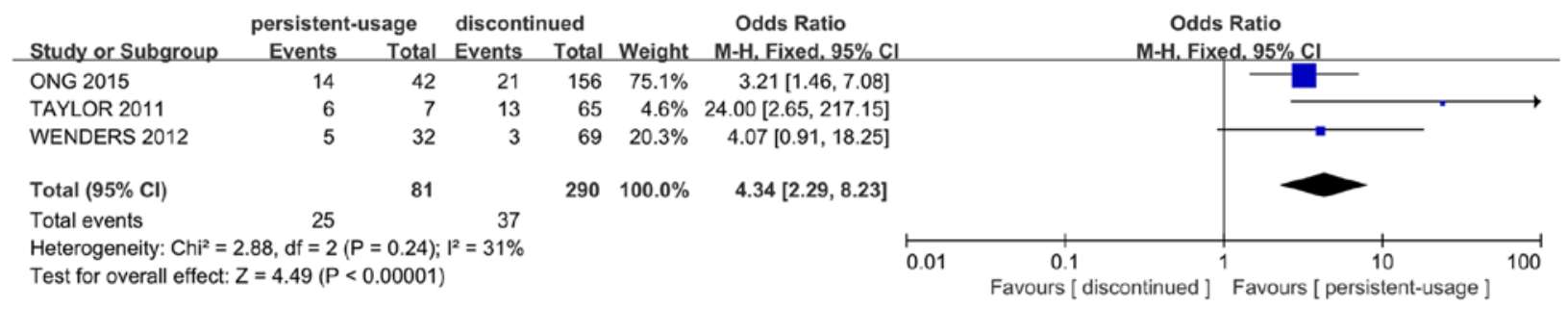

\section{B Blood transfusion rate}

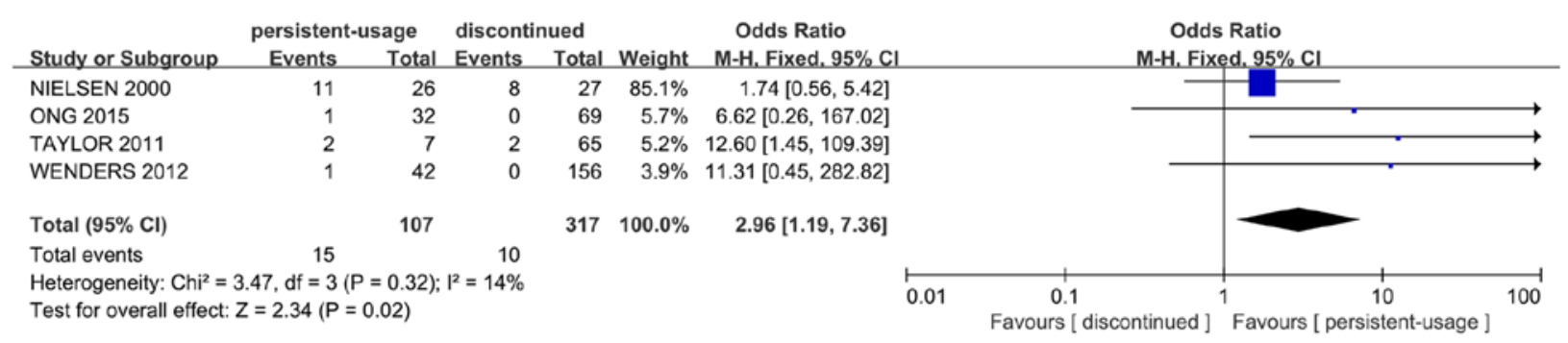

\section{Incidence of cardiovascular and cerebrovascular events}

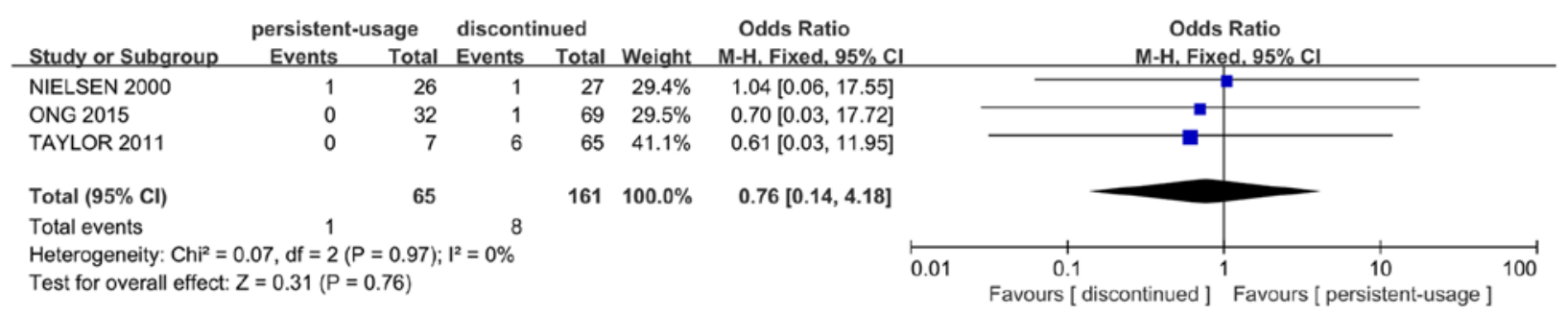

Figure 2. Meta-analysis of the comparison between persistent-usage group and discontinued group in TURP. The effect of persistent-usage and discontinued antithrombotic drugs on (A) incidence of postoperative bleeding, (B) blood transfusion rate and (C) incidence of cardiovascular and cerebrovascular events was analyzed. TURP, transurethral resection of the prostate.

\section{A Incidence of postoperative bleeding}

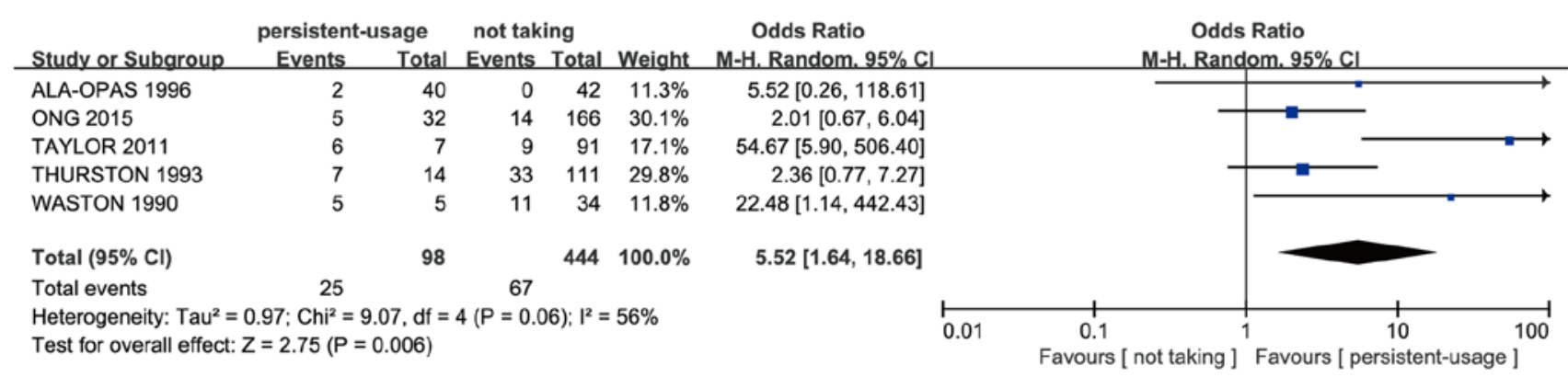

\section{B Blood transfusion rate}

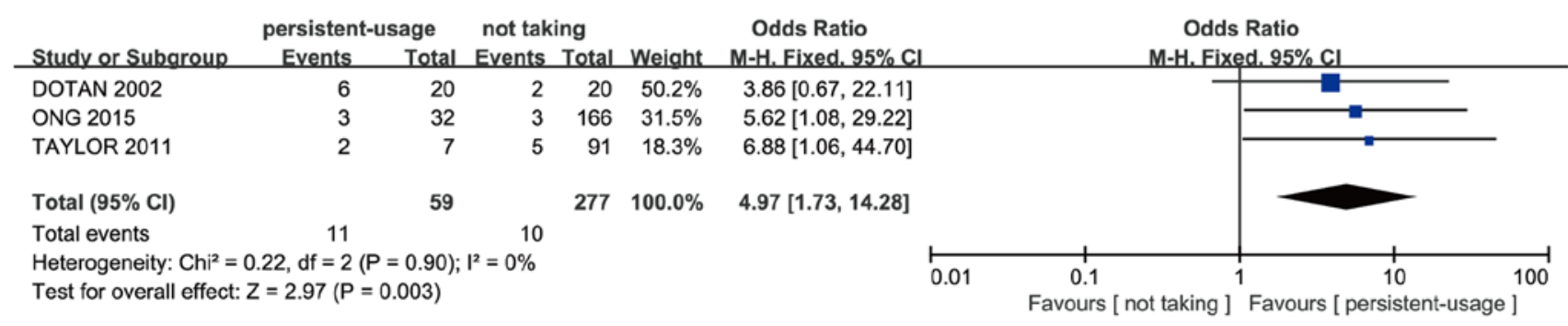

Figure 3. Meta-analysis of the comparison between persistent-usage group and not taking group in TURP. The effect of persistent-usage and unused antithrombotic drugs on (A) incidence of postoperative bleeding and (B) blood transfusion rate was analyzed. TURP, transurethral resection of the prostate. 


\section{A Blood transfusion rate}

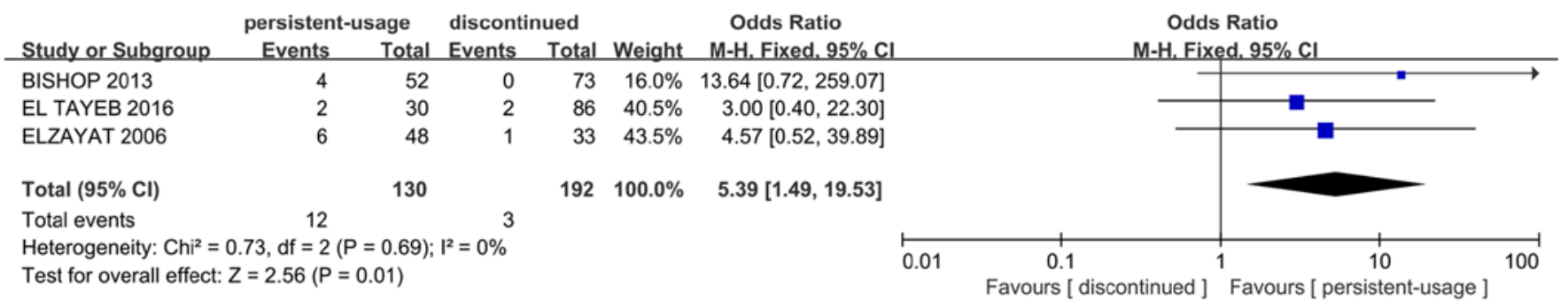

\section{B Decreased intraoperative hemoglobin}

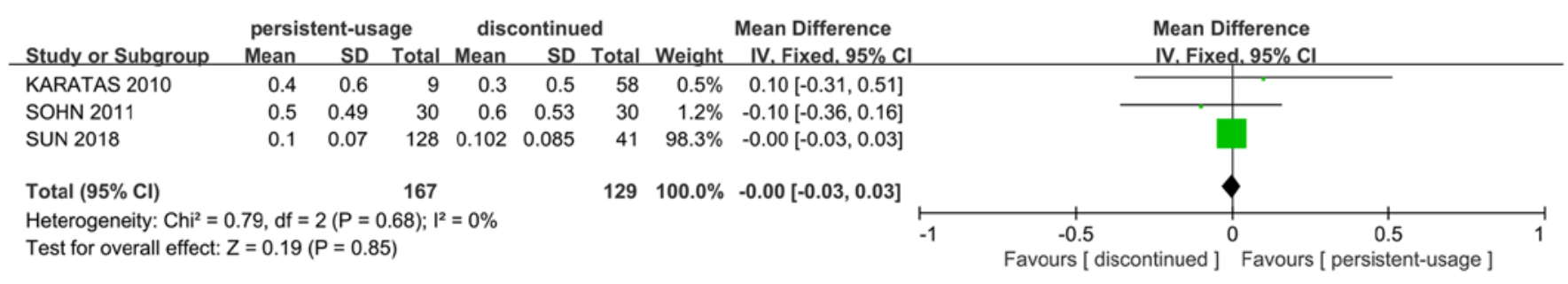

Figure 4. Meta-analysis of the comparison between persistent-usage group and discontinued group in laser surgery. The effect of persistent-usage and discontinued antithrombotic drugs on (A) blood transfusion rate and (B) decreased intraoperative hemoglobin was analyzed.

\section{A Blood transfusion rate}

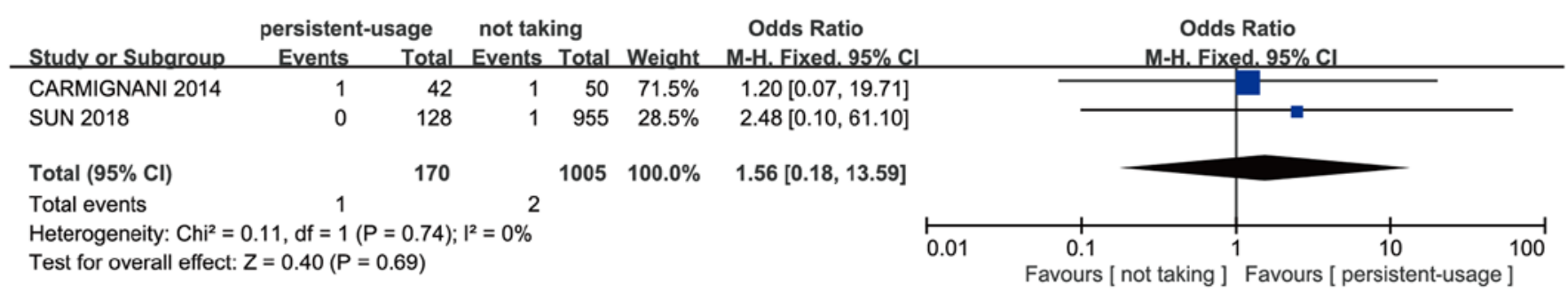

\section{B Catheterization duration}

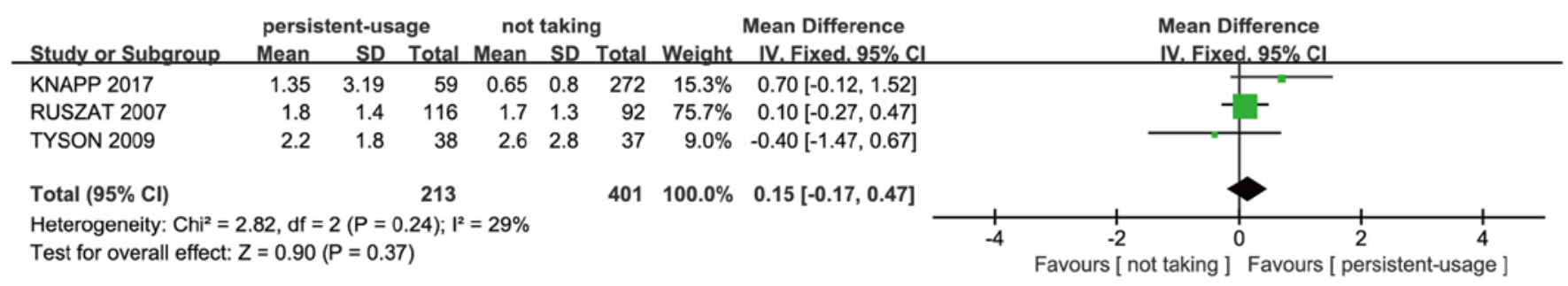

Figure 5. Meta-analysis of the comparison between persistent-usage group and not taking group in laser surgery. The effect of persistent-usage and unused antithrombotic drugs on (A) incidence of blood transfusion rate and (B) catheterization duration was analyzed.

ratio (INR) of the prothrombin time of patients in the study of Bishop et al (24) is 2.61, while the average INR of the remaining studies is less than or equal to 2.0. Elzayat et al (22) found that high INR and early postoperative recovery of warfarin may be the main causes of blood transfusion, but the average blood transfusion volume in the above studies was not large (2.5 and 3.7 units). In addition, the results of transfusion rate and decreased intraoperative hemoglobin were inconsistent because the studies of transfusion rate were different from the studies included in decreased intraoperative hemoglobin. The results of this meta-analysis showed that the continuous use of drugs during the perioperative period of laser surgery did not increase decreased intraoperative hemoglobin and catheterization duration. Therefore, continuous preoperative anticoagulation is safe and feasible for BPH patients treated with laser surgery. In addition, some studies have found that blood transfusion rates in patients undergoing laser surgery were lower than that in TURP, suggesting that 


\section{A Blood transfusion rate}

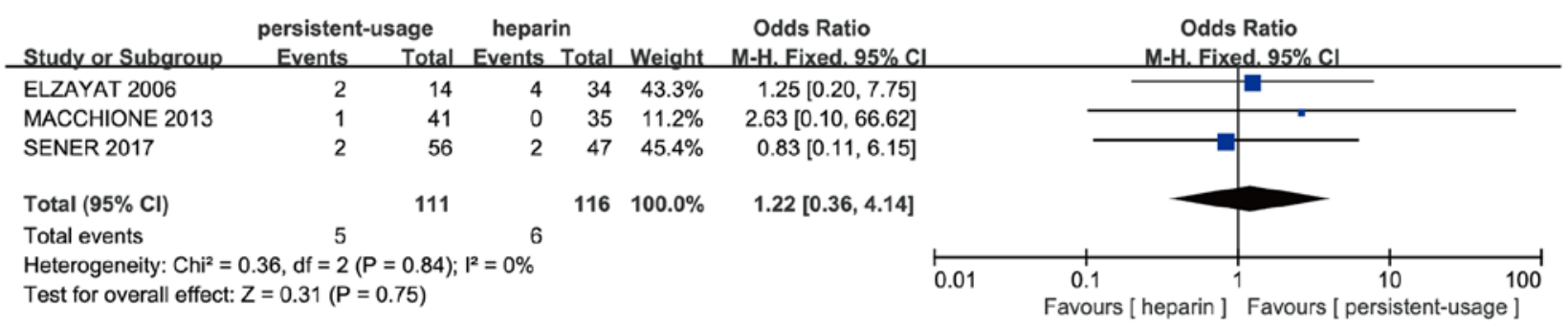

\section{B Decreased intraoperative hemoglobin}

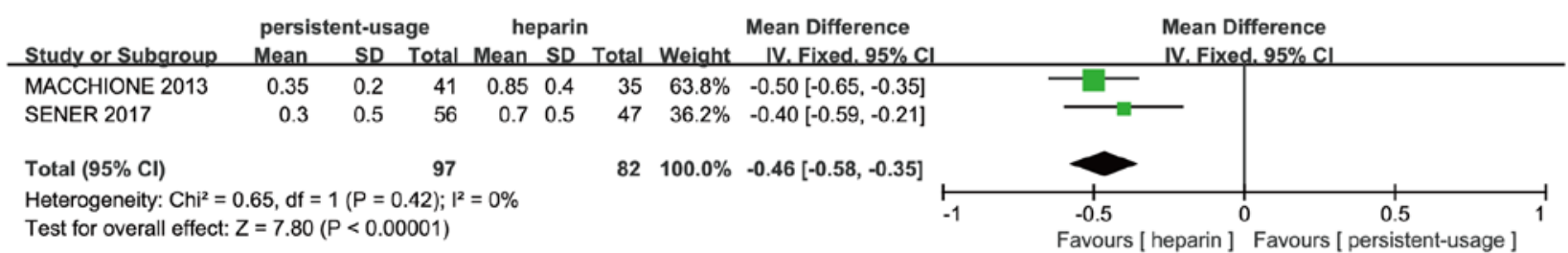

\section{Catheterization duration}

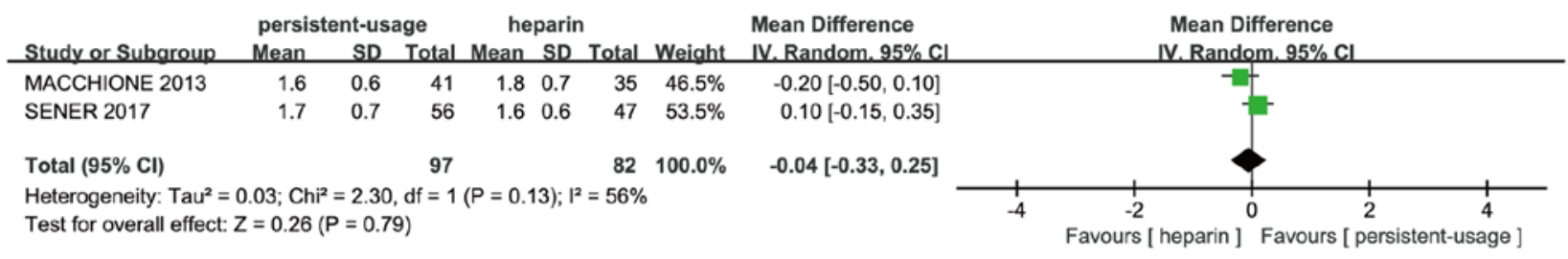

Figure 6. Meta-analysis of the comparison between persistent-usage group and heparin group in laser surgery. Analysis of the effect of persistent-usage and unused heparin replacement on (A) incidence of blood transfusion rate, (B) decreased intraoperative hemoglobin and (C) catheterization duration.

the risk of bleeding from laser surgery is lower than that in TURP (36,37). This may be because the laser has a deeper solidification depth. The solidification depth of $2 \mu \mathrm{m}$ laser is $\sim 0.5-1.0 \mathrm{~mm}$, while the solidification depth of TURP is $\sim 0.29 \mathrm{~mm}$ (38).

It is also controversial whether heparin should be used during the discontinuation of antithrombotic drugs. Ong et al (20) believed that compared with the discontinuation of antithrombotic drugs, low molecular weight heparin replacement during the perioperative period of TURP would lead to higher postoperative bleeding complications (44 vs. 0\%) and higher thrombotic complications (17 vs. 0\%), while Dotan et al (18) considered that low molecular weight heparin replacement during TURP would only slightly extend the hospital stay and not lead to the increase of intraoperative and postoperative bleeding events. This meta-analysis found that in the laser BPH surgery perioperative period, there was no obvious difference in blood transfusion rate and catheterization duration between persistent-usage and heparin group, but heparin replacement promotes the drop in intraoperative hemoglobin, which reduced the value of low molecular weight heparin replacement in laser surgery. In general, the safety of low molecular weight heparin replacement in laser surgery is similar to that of traditional antithrombotic drugs, except for the effect on intraoperative hemoglobin. Therefore, we believe that low molecular weight heparin replacement should be avoided when it is not necessary. For patients at high risk of thrombosis, the surgeon may prescribe low molecular weight heparin in appropriate amounts.

As meta-analysis is an observational study, its results may be affected by bias, confounding and other factors. The limitations of this paper are as follows: i) Most of the included studies were based on the risk of cardiovascular and cerebrovascular disease in each patient to decide whether to stop antithrombotic drugs, resulting in our inability to analyze the risk of thrombosis after drug withdrawal; ii) Prostate volume, preoperative application of $5 \alpha$ reductase inhibitors, preoperative indwelling catheter have been shown to affect bleeding after prostate surgery, this meta-analysis did not consider these factors.

In conclusion, the discontinuation of antithrombotic drugs during the perioperative period of TURP can reduce the risk of postoperative bleeding; however, the risk of cardiovascular and cerebrovascular thrombosis and embolism after discontinuation should be carefully evaluated preoperatively. Continuous use of antithrombotic drugs during the perioperative period of laser BPH surgery is safe and feasible, and can be used as the preferred BPH surgical treatment for patients with high-risk cardiovascular and cerebrovascular diseases. There is controversy over the need for transitional treatment during the discontinuation of antithrombotic drugs. However, due to the limitations of the quality of the included studies, 
more high-quality studies are needed to verify the above conclusions.

\section{Acknowledgements}

Not applicable.

\section{Funding}

No funding was received.

\section{Availability of data and materials}

All data generated or analyzed during this study are included in this published article.

\section{Authors' contributions}

QH designed the study and wrote the manuscript. YY and FG acquired and analyzed the data. All authors read and approved the final manuscript.

\section{Ethics approval and consent to participate}

Not applicable.

\section{Patients consent for publication}

Not applicable.

\section{Competing interests}

The authors declare that they have no competing interests.

\section{References}

1. Mobley D, Feibus A and Baum N: Benign prostatic hyperplasia and urinary symptoms: Evaluation and treatment. Postgrad Med 127: 301-307, 2015.

2. Kim EH, Larson JA and Andriole GL: Management of benign prostatic hyperplasia. Annu Rev Med 67: 137-151, 2016.

3. Aaron L, Franco OE and Hayward SW: Review of prostate anatomy and embryology and the etiology of benign prostatic hyperplasia. Urol Clin North Am 43: 279-288, 2016.

4. Rauch $M$ and Strunk H: Interventional treatment of benign prostatic hyperplasia: Embolization of the testicular vein. Radiologe 57: 652-658, 2017 (In German).

5. Bach T, Xia SJ, Yang Y, Mattioli S, Watson GM, Gross AJ and Herrmann TR: Thulium: YAG 2 mum cw laser prostatectomy: where do we stand? World J Urol 28: 163-168, 2010.

6. Nunes R, Oliveira R, Carneiro A, Neto AM, Antunes AA, Bernardo WM and Silvinato A; Brazilian Society of Urology: Benign prostatic hyperplasia: Laser prostatectomy (PVP). Rev Assoc Med Bras (1992) 63: 929-940, 2017.

7. Skagseth E Jr: Retropubic prostatectomy. A clinical review and follow-up study. Nord Med 77: 621-624, 1967 (In Norwegian).

8. Romero-Otero J, García-González L, García-Gómez B, Justo-Quintas J, García-Rojo E, González-Padilla DA, Sopeña-Sutil R, Duarte-Ojeda JM and Rodríguez-Antolín A: Factors influencing intraoperative blood loss in patients undergoing holmium laser enucleation of the prostate (HoLEP) for benign prostatic hyperplasia: A large multicenter analysis. Urology 132: 177-182, 2019.

9. Meskawi M, Hueber PA, Valdivieso R, Karakiewicz PI,Pradere B, Misrai V, Chughtai B and Zorn KC: Complications and functional outcomes of high-risk patient with cardiovascular disease on antithrombotic medication treated with the 532-nm-laser photo-vaporization Greenlight XPS-180 W for benign prostate hyperplasia. World J Urol 37: 1671-1678, 2019.
10. Biondi-Zoccai GG, Lotrionte M, Agostoni P, Abbate A, Fusaro M, Burzotta F, Testa L, Sheiban I and Sangiorgi G: A systematic review and meta-analysis on the hazards of discontinuing or not adhering to aspirin among 50,279 patients at risk for coronary artery disease. Eur Heart J 27: 2667-2674, 2006.

11. Proietti M, Mairesse GH, Goethals P, Scavee C, Vijgen J, Blankoff I, Vandekerckhove Y and Lip GY; Belgian Heart Rhythm Week Investigators: Cerebrovascular disease, associated risk factors and antithrombotic therapy in a population screening cohort: Insights from the Belgian Heart Rhythm Week programme. Eur J Prev Cardiol 24: 328-334, 2017.

12. Stang A: Critical evaluation of the Newcastle-Ottawa scale for the assessment of the quality of nonrandomized studies in meta-analyses. Eur J Epidemiol 25: 603-605, 2010.

13. Watson CJ, Deane AM, Doyle PT and Bullock KN: Identifiable factors in post-prostatectomy haemorrhage: The role of aspirin. Br J Urol 66: 85-87, 1990.

14. Thurston AV and Briant SL: Aspirin and post-prostatectomy haemorrhage. Br J Urol 71: 574-576, 1993.

15. Ala-Opas MY and Grönlund SS: Blood loss in long-term aspirin users undergoing transurethral prostatectomy. Scand J Urol Nephrol 30: 203-206, 1996.

16. Nielsen JD, Holm-Nielsen A, Jespersen J, Vinther CC, Settgast IW and Gram J: The effect of low-dose acetylsalicylic acid on bleeding after transurethral prostatectomy - a prospective, randomized, double-blind, placebo-controlled study. Scand J Urol Nephrol 34: 194-198, 2000.

17. Wenders M, Wenzel O, Nitzke T and Popken G: Perioperative platelet inhibition in transurethral interventions: TURP/TURB. Int Braz J Urol 38: 606-610, 2012.

18. Dotan ZA, Mor Y, Leibovitch I, Varon D, Golomb J, Duvdevani M and Ramon J: The efficacy and safety of perioperative low molecular weight heparin substitution in patients on chronic oral anticoagulant therapy undergoing transurethral prostatectomy for bladder outlet obstruction. J Urol 168: 610-614, 2002.

19. Taylor K, Filgate R, Guo DY and Macneil F: A retrospective study to assess the morbidity associated with transurethral prostatectomy in patients on antiplatelet or anticoagulant drugs. BJU Int 108 (Suppl 2): 45-50, 2011.

20. Ong WL, Koh TL, Fletcher J, Gruen R and Royce P: Perioperative management of antiplatelets and anticoagulants among patients undergoing elective transurethral resection of the prostate - A single institution experience. J Endourol 29: 1321-1327, 2015.

21. Carmignani L, Macchi A, Ratti D, Finkelberg E, Casellato S, Bozzini G, Maruccia S, Marenghi C and Picozzi S: Are histological findings of thulium laser vapo-enucleation versus transurethral resection of the prostate comparable? Pathol Oncol Res 21: 1071-1075, 2015.

22. Elzayat E, Habib E and Elhilali M: Holmium laser enucleation of the prostate in patients on anticoagulant therapy or with bleeding disorders. J Urol 175: 1428-1432, 2006.

23. Tyson MD and Lerner LB: Safety of holmium laser enucleation of the prostate in anticoagulated patients. J Endourol 23: 1343-1346, 2009.

24. Bishop CV, Liddell H, Ischia J, Paul E, Appu S, Frydenberg M and Pham T: Holmium laser enucleation of the prostate: Comparison of immediate postoperative outcomes in patients with and without antithrombotic therapy. Curr Urol 7: 28-33, 2013.

25. El Tayeb MM, Jacob JM, Bhojani N, Bammerlin E and Lingeman JE: Holmium laser enucleation of the prostate in patients requiring anticoagulation. J Endourol 30: 805-809, 2016.

26. Sun J, Shi A, Tong Z and Xue W: Safety and feasibility study of holmium laser enucleation of the prostate (HOLEP) on patients receiving dual antiplatelet therapy (DAPT). World J Urol 36: 271-276, 2018.

27. Ruszat R, Wyler S, Forster T, Reich O, Stief CG, Gasser TC, Sulser T and Bachmann A: Safety and effectiveness of photoselective vaporization of the prostate (PVP) in patients on ongoing oral anticoagulation. Eur Urol 51: 1031-1038, 2007.

28. Karatas OF, Alkan E, Horasanli K, Luleci H and Sarica K: Photoselective vaporization of the prostate in men with a history of chronic oral anti-coagulation. Int Braz J Urol 36: 190-197, 2010.

29. Sohn JH, Choi YS, Kim SJ, Cho HJ, Hong SH, Lee JY, Hwang TK and Kim SW: Effectiveness and safety of photoselective vaporization of the prostate with the $120 \mathrm{~W}$ HPS Greenlight laser in benign prostatic hyperplasia patients taking oral anticoagulants. Korean J Urol 52: 178-183, 2011.

30. Knapp GL, Chalasani V and Woo HH: Perioperative adverse events in patients on continued anticoagulation undergoing photoselective vaporisation of the prostate with the 180 -W Greenlight lithium triborate laser. BJU Int 119 (Suppl 5): 33-38, 2017. 
31. Macchione L, Mucciardi G, Gali' A, Di Benedetto A, Butticè S and Magno C: Efficacy and safety of prostate vaporesection using a 120-W 2- $\mu$ m continuous-wave Tm:YAG laser (RevoLix 2) in patients on continuous oral anticoagulant or antiplatelet therapy. Int Urol Nephrol 45: 1545-1551, 2013.

32. Sener TE, Butticè S, Macchione L, Netsch C, Tanidir Y, Dragos L, Pappalardo R and Magno C: Thulium laser vaporesection of the prostate: Can we operate without interrupting oral antiplatelet/ anticoagulant therapy? Investig Clin Urol 58: 192-199, 2017.

33. KaciulyteJ,LoscoL,MarucciaM,DeliaG,LoTortoF,DiTarantoG, Caputo GG, Berchiolli R, Ribuffo D and Cigna E: Postsurgical antithrombotic therapy in microsurgery: Our protocol and literature review. Eur Rev Med Pharmacol Sci 23: 4448-4457, 2019.

34. Ondeck NT, Bohl DD, McLynn RP, Cui JJ, Bovonratwet P, Singh K and Grauer JN: Longer operative time is associated with increased adverse events after anterior cervical diskectomy and fusion: 15-minute intervals matter. Orthopedics 41: e483-e488, 2018.

35. Catanzarite T, Saha S, Pilecki MA, Kim JY and Milad MP: Longer operative time during benign laparoscopic and robotic hysterectomy is associated with increased 30-day perioperative complications. J Minim Invasive Gynecol 22: 1049-1058, 2015.
36. Bruyère $F$, Huglo $D$, Challacombe $B$, Haillot $\mathrm{O}$, Valat $\mathrm{C}$ and Brichart N: Blood loss comparison during transurethral resection of prostate and high power GreenLight $\left({ }^{\mathrm{TM}}\right)$ laser therapy using isotopic measure of red blood cells volume. J Endourol 25 : 1655-1659, 2011.

37. Ruszat R, Wyler SF, Seitz M, Lehmann K, Abe C, Bonkat G, Reich O, Gasser TC and Bachmann A: Comparison of potassium-titanyl-phosphate laser vaporization of the prostate and transurethral resection of the prostate: update of a prospective non-randomized two-centre study. BJU Int 102: 1432-1439, 2008.

38. Wendt-Nordahl G, Huckele S, Honeck P, Alken P, Knoll T, Michel MS and Häcker A: Systematic evaluation of a recently introduced 2-microm continuous-wave thulium laser for vaporesection of the prostate. J Endourol 22: 1041-1045, 2008.

This work is licensed under a Creative Commons Attribution-NonCommercial-NoDerivatives 4.0 International (CC BY-NC-ND 4.0) License. 